\title{
RECONNECTING YOUNG PEOPLE WITH LEARNING: A SOCIAL CAPITAL APPROACH IN VET
}

\author{
Stephen Black, Jo Balatti and Ian Falk
}

\begin{abstract}
This paper contributes to pedagogical debates on how to meet the learning needs of young people who are disconnected from school. It presents a case study of a program which aimed to prepare students for their Year 10 equivalent school leaving qualification in a basic education section of a Technical and Further Education (TAFE) college in Australia. Most of the students were between 15 and 17 years of age, had experienced literacy and numeracy difficulties in formal learning, and for various reasons were disconnected from the school system. The paper explains how an approach to learning in VET led to important human and social capital outcomes, and in particular, a changed sense of efficacy on the part of students in the program. The two key elements of this VET pedagogy were: individualised, self-paced learning within a flexible program structure; and the fostering of social capital, including mutual trust and respect, through the course-related learning network of teachers and students and other influential networks, including peer networks. Analysis of interview transcript data with students and teachers revealed the mutually reinforcing role of these elements of VET pedagogy.
\end{abstract}

\section{KEY WORDS}

disconnected young people, social capital, self efficacy, networks

\section{INTRODUCTION}

This paper describes a pedagogical approach to meeting the learning needs of young people who are disconnected from school and the broad range of outcomes it produced. It features a youth program in an Australian TAFE college, and the data presented in this paper are based on the perspectives of a group of young people and their teachers in that program. All the students were enrolled concurrently in a basic skills (literacy and numeracy) course and the Certificate in General Vocational Education (CGVE). The courses were taught in the TAFE college as part of a foundation education program that was described as 'flexible', and which provided young people with an alternative pathway to the Year 10 qualification that is considered a prerequisite to entry into so many occupations and further education. All the students on the program had for various reasons left school and they could be considered disconnected from school. In this paper we have used the term 'disconnected' (and its corollary, 'connected') because it fits well with the social capital understanding of 'connections' people have as members of networks. Although most young people continue at school at least to year 10, where (in New South Wales) they complete the School Certificate, for some young people, the school system does not meet their needs, and this study involved students who fell into this category. 


\section{Youth studies and what works}

There are many reports both overseas and in Australia on how to meet the education and future work needs of young people. A recent British study of 'Pathfinder' programs, which provide vocational training in further education colleges for young people still at school, suggests success in these programs 'is due to a pedagogy that makes use of experiential and social forms of learning in an environment which allows students to connect more fully to a future adult world' (Lumby 2007:1). Young people in these programs said they were treated with 'respect' and they felt the vocational teachers trusted them. Another British study (Spielhofer et al 2009) suggests a number of 'good practice' guidelines to re-engage young people who are not in education, employment or training (NEET), including non-formal learning, flexible programs structures, individual planning and the employment of staff who can make learning fun and enjoyable.

Recent Australian studies follow similar themes. In Victoria for example, one study (Volkoff et al 2006) calls for the use of adult learning principles, integrated literacy and numeracy, learning support and pathways planning. They also suggest 'recognition of students' individuality, mutual respect and the need for a significant connection with at least one staff member' (p.3). A report by the Australian Capital Territory Department of Education and Training has recently rejected the idea of raising the school leaving age as a means of re-engaging young people in education. Instead, they suggest the need for 'alternative pathways and increased support for students for whom remaining at school is not a viable option' (ACT Department of Education and Training 2009:2).

There are a number of key elements in the above recommendations and initiatives for young people who find the school system does not meet their needs, including the need for flexible program structures, alternative pathways, integrated literacy and numeracy, support mechanisms, and most importantly, a strong individualised connection or relationship between teachers and students. All of these elements resonate with the program examined in this paper, and particularly the final element dealing with teacher-student relationships. Highlighting this element, was one Australian report on young people engaged in study in VET entitled Life is respect (Bradshaw 1999). It would seem that mutual respect, trust and the important 'connection' teachers and students make with one another are as significant as any pedagogical techniques or methods in enabling some of the most disaffected students to re-connect with learning (see Chodkiewicz, Widin and Yasukawa 2010). Some parallels may be apparent here with the work of youth workers, that is, the relationship rather than the service becomes the priority (see Rodd and Stewart 2009). How people relate with one another and with whom forms the basis of what we term social capital.

\section{The role of social capital}

Portes (1998:7) observes that, "Whereas economic capital is in people's bank accounts and human capital is inside their heads, social capital inheres in the structure of their relationships.” Conceptually, however, social capital is contested and its role varies considerably in the research literature. Bourdieu (1986), for example, associates social capital (along with cultural and economic capital) with the reproduction of unequal power relations in society and thus social class divisions. Coleman (1988) also illustrates its relationship to power, showing how educational attainment and school retention rates relate to the extent to which different social groups can draw on social capital. Putnam (2000) has been largely responsible for popularising 
the concept, in particular for linking the decline in community group membership to the decline in social capital. In the research study on which this paper is based, we were advised by our national funding organisation to draw on the work of the Australian Bureau of Statistics (2004) on social capital. Thus, we adopted the definition provided by the Australian Bureau of Statistics (2004:5), which in turn was drawn from the OECD (2001:41), which refers to social capital as 'networks, together with shared norms, values and understandings which facilitate cooperation within or amongst groups.' This is a definition which sees connections or network relations between people as a valuable resource, which combined with other forms of capital (e.g. human capital), can lead to the well-being of individuals, communities, and even nations (OECD 2001). In this paper the focus is primarily on the benefits for individuals, that is, social capital as a private good.

Two previous studies by the authors in VET contexts (Balatti, Black and Falk 2006, 2009) explored the relationship between learning and social capital. In our first research study which examined social capital outcomes for different groups of students in VET courses (Balatti, Black and Falk 2006), we adapted a framework developed by the Australian Bureau of Statistics (2004:14) to identify social capital outcomes. This framework categorised social capital into four different groupings: network qualities, network structure, network transactions and network types (see Table 1 from Balatti, Black and Falk 2006: 17). Changes in the right hand column of Table 1 (column heading: Indicators for the study) that students attributed to participation in VET courses were defined as social capital outcomes.

\section{Table 1: Application of ABS Social Capital Framework}

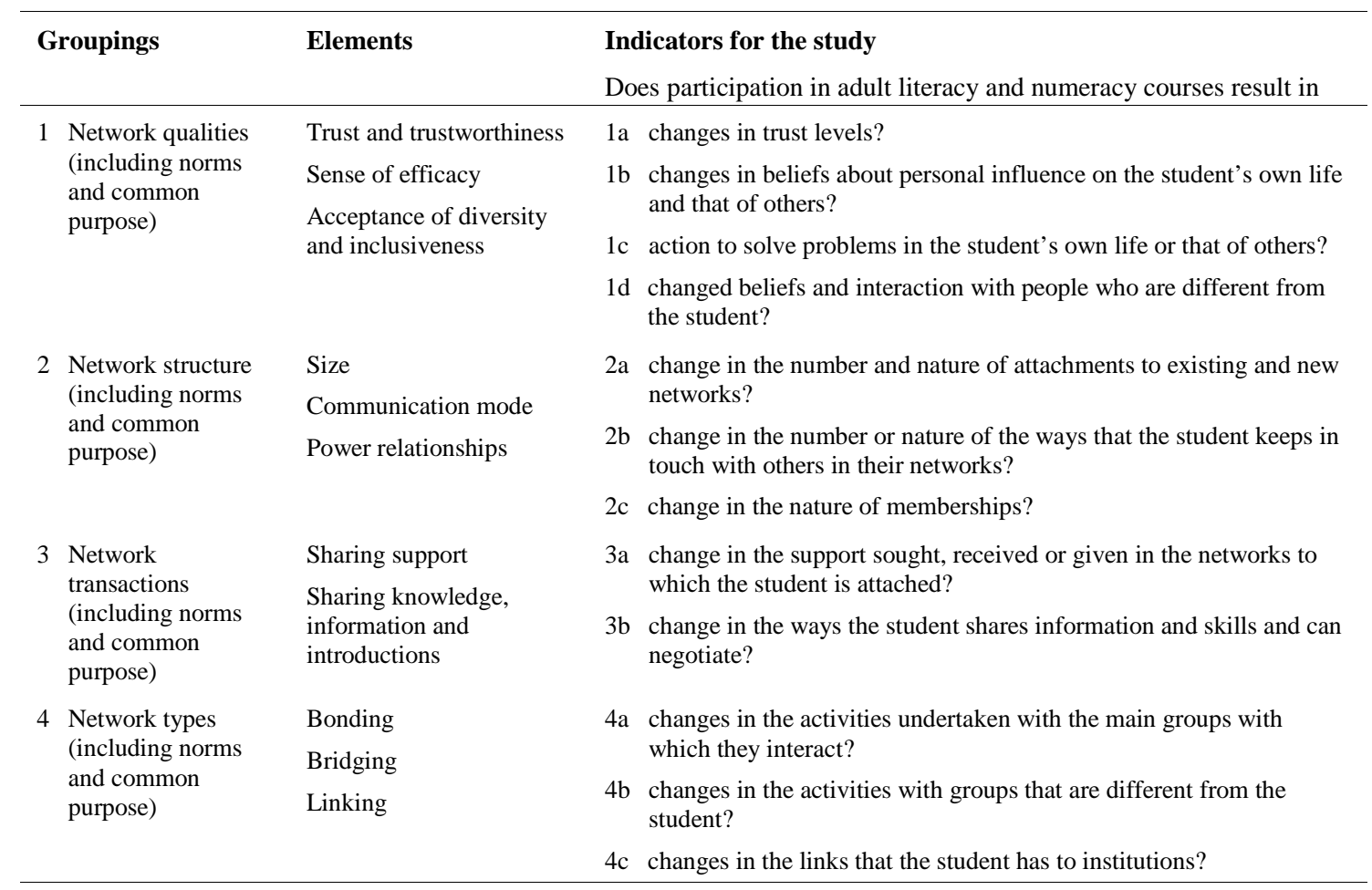


The interview data in this first study demonstrated several course-related networks that resulted in social capital outcomes. There was the formal classroom network of students and teachers interacting together, the network of students interacting with other students, and the informal network of teachers interacting with students, often after class or outside the classroom. It was the group norms and the nature of the interactions operating in these course-related networks that provided a safe and potentially productive 'practice field' for students to redefine themselves and their relationships with others (Balatti, Black and Falk 2006:36). These course-related networks also encouraged bridges and links between the course experience and the lives of students beyond the classroom, for example, in workplaces and in the community.

Our second study highlighted the role of social capital in relation to adult literacy partnerships, policy and pedagogy, and a set of guidelines was developed to enhance the potential for social capital outcomes (Balatti, Black and Falk 2009, Balatti and Black forthcoming). For teachers, a social capital approach involved conceptualising learners as members of networks, and the new course-related learning network was the key one where they could influence the learning outcomes. The main teaching strategies involved fostering relationship-building among students and teachers (i.e. bonding ties that build cohesion and a common purpose within groups), and providing a respectful, safe and supportive learning environment. The guidelines for teaching also included drawing on the previous experiences and interests of students, that is, their existing networks, and linking with potentially new networks beyond the classroom. We can call these bridging and linking ties. Bridging ties are the relatively weaker ties between groups or that an individual has with members of groups that are not his/her main groups. Linking ties are the ties that people are able to make with private and public institutions and systems that are important to their capacity to participate more fully in society (Balatti, Black and Falk 2009:14).

\section{Youth studies and social capital}

In view of the contested nature of social capital, the approach and understandings outlined in the research in this paper need to be seen to represent but one approach of many in the increasing number of studies which draw on social capital concepts in the study of young people. StantonSalazar (1997), for example, in a broad discussion paper, draws on Bourdieu's work in analysing the role of networks in reproducing exclusion and subordination for minority children and adolescents. As Stanton-Salazar (1997:3) notes, 'networks are implicated at every turn' in making problematic minority children and young people's access to the social capital and institutional support that lead to privilege and power. In another broader discussion of social capital and young people, Bassani (2007) analyses the social capital literature and provides a caution for studies that show clear links between social capital and well-being for young people, suggesting the well-being of young people is highly complex and not reducible to such linear relationships. Bassani sees social capital theory as a useful tool, but claims it has not been adequately tested, taking into account, for example, exogenous factors such as gender, age, culture and ethnicity in the formation of social capital.

Several studies have focused specifically on social capital and young people involved in vocational education. For example, a recent Australian study by Bexley, Marginson and Wheelahan (2007) largely follows Bourdieu's approach to social capital, and shows the 'differential performativity' of the social capital of some groups of VET and higher education students. 'New economy' (Business and Information Technology) students, due partly to their non-English speaking backgrounds and parental education levels, were found to have less access 
to the family networks that could help them with their studies. The social capital of VET students was also found to be less productive compared with higher education students in relation to obtaining employment, due to the absence of factors such as 'friends of friends' networks that can lead to employment. Raffo (2003) in a UK study, examines the experiences of young people in flexible educational programs which incorporate a work experience component. He shows how supportive workplace networks may contrast with those the students experience at school, thus for some students hindering their re-engagement with schooling. Catts (2009) shows how weak social capital in terms of bridging and linking ties is a barrier to young people obtaining further education and work.

\section{RESEARCH METHOD}

This particular youth program was chosen as a site for research because, through word of mouth within the host TAFE Institute, and in particular with Access department staff (adult literacy/numeracy, ESOL, outreach), it was considered to be a successful program for reconnecting disaffected young students with education. However, no claims are made that the program is typical of youth programs in TAFE. The research was approved by the Human Research Ethics Committee at James Cook University, Townsville.

The data were based on semi-structured interviews conducted over a two week period in mid 2005 with a selection of 13 young people who attended the TAFE college program and a group of five teachers on the program. Each interview lasted between 30 and 40 minutes, and with the signed permission of participants, the interviews were taped and later transcribed in full. Students were selected for interview based on their availability on the days of interviews, and on the recommendation of the teachers rostered on duty at the time. One student refused to be interviewed, citing that he was too busy. All interviews were conducted in a vacant teacher's office next to the main teaching areas.

The interviews with students sought information on their perceptions of the program. For example, they were asked why they came to the course, what they got out of the program, how they used what they had learnt at home and in other contexts, what, if any, changes they had experienced personally as a result of participating in the program, and why and how the program was important to them. Teacher interviews included questions on what they taught, what they thought their students got out of the program, what changes they had observed in their students inside and outside of the classroom, and what sort of teaching strategies worked well with these students. Learning outcomes in the interview transcript data were then analysed and coded according to two sets of indicators: The first was the social capital indicators of change using the ABS (2004) Social Capital Framework (see Table 1 in this paper). The second was the OECD (1982) indicators of socio-economic well-being which are categorised according to the following bands: health, education and learning, employment and quality of life, time and leisure, command over goods and services, physical environment, social environment, and personal safety (see Balatti, Black and Falk 2006:17). Teaching strategies were coded according to themes emerging from the data.

The student interview sample comprised seven female and six male students (13 total). The mean age of the student group was 18 years, and the oldest member was 23 years (5 years older than the next oldest member). Four students were 15 years of age, and two were 16 years of age. The remaining participants began their TAFE studies before they were 17 years of age. For all of the 
students except one, their first language was English. All of the five female teachers interviewed were very experienced in adult basic education work, with two having taught in this field for 20 years, and the others with 15, 8 and 5 years experience respectively. Pseudonyms are used throughout the paper.

\section{FINDINGS AND DISCUSSION}

In this section we first describe how the students felt they were disconnected from school. Then we consider some of the outcomes of the program, and follow this with an analysis of the various elements of the learning environment which, from the students' and teachers' perspectives appear to have contributed to these outcomes.

\section{Young people disconnected from school}

A defining feature of these students was their disconnection from the school system. The circumstances that brought the students to the TAFE college were often quite different, but their underlying dispositions towards formal schooling were often similar. Not surprisingly, some students spoke of their dislike of being 'talked down' to by school teachers, and others had been in trouble of some sort and their schools had provided the 'push' factor and basically asked them to leave school. Other students, whilst not rebellious or in trouble at school, found they were unable to cope with the school system. One boy suffered bullying at school, and others said they were simply 'sick of school and the teachers there' and they were truanting so much there was little point in staying. While the 'at risk' label may be applied to some of these students, it would be inaccurate to generalise across all the students. What was clear though, was that school hadn't worked for these young people, and TAFE provided them with an alternative path to complete their formal Year 10 level schooling.

\section{Program outcomes}

Course outcomes can be seen to comprise two main types: human capital and social capital, and both were evident from the interviews conducted in this study. Human capital outcomes are usually associated with the acquisition of qualifications and skills which in turn can lead to improved economic benefits. One of the key course outcomes for these students was obtaining their CGVE (Year 10 equivalent) which demonstrated they had acquired a requisite level of academic skills, and in particular, literacy and numeracy skills. However, it is difficult to be definitive about this outcome for this group of students because the interviews were conducted at a time when they were working towards obtaining their CGVE. From student and teacher comments, it would seem most students who undertook the program either completed their CGVE, gained employment or were accepted into a vocational course. Unfortunately no data were available for course completions or employment outcomes from previous years. For many of the students interviewed, completing the CGVE was simply a foregone conclusion based on their progress in the course to date. Elle, for example, stated she had 'only got another two or three weeks to go', and Sophie said she would finish 'hopefully, first or second week next term.' As a reflection of the inevitability of gaining their CGVE, many students had clear plans for what they wanted to do beyond the CGVE. Some comments included:

When I finish here, I'm going straight into the Reserves (Army) and go as far as I can in the Reserves. (Patrick) 
I want to do a computer course after this. (Elle)

As soon as I finish this, I plan to start a Diploma in Childcare through TAFE. (Sophie)

Other students planned to continue their studies to the next level beyond Year 10 (the Higher School Certificate - HSC) or get an apprenticeship (Plumbing and Electrical were mentioned). Interestingly, and quite remarkably, considering the background of these students, it was not unusual for students to rejoin the school system for further studies, and one of the teachers said that 'quite a few' students from the previous year had gone back to school to do their HSC. One of the students interviewed had actually tried to go back to school whilst on the TAFE program, and the only factor holding her back was the school insisting she repeat a year: 'Like, I want to go back to school now, but I couldn't because I wanted to be in the year that I was in' (Georgia). Going back to school after previously being disconnected from it was a surprising and significant outcome.

This outcome, returning to the school system, provides an important link with other less tangible course outcomes relating to the second main type of course outcomes, social capital outcomes. For example, one of the teachers explained how a former student with a previous drug habit had obtained her Year 10 at TAFE and then returned for a social visit:

She came in the other day in a school uniform, and I said, 'How are you going, wearing your uniform and having to be in class?' And she said, 'Nah, it's cool, it's cool. I feel good now. I know where I'm going.' So, it's like, I think they just feel better about themselves and more confident and therefore they're not as angry, therefore they're happy, and they'll take it.

What this anecdote appears to demonstrate is how this student considered she had changed as a person, how she felt about herself, and as a consequence, how she related with others in her networks. It was certainly the opinion of her former teacher, who knew her very well, that this anecdote indicated a significant identity shift on the part of the student. Quite a few other students in the interviews similarly demonstrated strong personal changes that affected how they related with others in their social networks.

These changes in network qualities can be seen to fall largely within the social capital indicator referred to as 'sense of efficacy' i.e. action to solve problems in the student's own life or that of others (see Table 1). Bandura (1995:2) defines self efficacy as 'the belief in one's capabilities to organise and execute the courses of action required to manage prospective situations.' In other words, it relates to a person's belief in their ability to succeed in particular situations. These young people seemed to be taking greater control of their lives, and took personal responsibility for their actions and how their actions might affect others. Georgia, for example, the young girl who wanted to return to school, stated 'I'm so different, it's not funny. I'm more mature, I'm more independent.' Another student, Sophie, also expressed how she felt better about herself and her ability to take control over her life:

I'm actually a lot more proud of myself because I know I'm doing this all on my own ... a lot more self confident in myself to know that I can actually come and do 
something without being made to go and do it. It's a choice that I make and it makes me feel better.

Tom was a student in a fair bit of trouble at school, and he was basically told by that school to leave. He explained how he felt he had changed on this program: 'Well, the idea that I can actually work without [being told] ... just kind of rely on myself more to get the work done. It's up to me to get it done.' He also suggested he wasn't 'so aggressive' and explained that he didn't 'get into that much trouble anymore either.'

The above quotes from interviews are indications that students had changed in their beliefs about their own personal influence on their lives, and how they were prepared to act to solve problems in their lives. These course outcomes link directly to the social capital outcomes grouped in Table 1 as network qualities, and include a sense of efficacy.

In many cases, the course had enabled students to relate better with adults, especially teachers, and as a consequence some students obtained part time work (examples of 'beliefs and interaction with people who are different from oneself' - see Table 1). Patrick for example, had previously found it difficult to interact with adults because he felt they would treat him in the same disrespectful way that he considered he was treated at school:

Oh, when I was at school I figured that older people, adults who have power over me, would all be like that. But now, once I come here, I seen that they can treat you as though ... treat me the way they should ... I treat them (other people) with a lot more respect, because I realise they're not all like that.

It was Patrick's new found ability to interact with 'authority figures' which he said was a factor enabling him to obtain part time work as a landscaper and builder. Another student, Elle, had never been able to discuss her personal problems with adults before, but now she felt more confident to do so, 'just like counsellors and, you know, all that. Like I never used to be able to talk in general about life and, you know, problems I had.’

These changes to how the young people related to adults were often linked to newly developed trust. Not only were some students beginning to trust others, including 'authority figures', but others were trusting them. Patrick for example, stated in relation to his mother: 'She's sort of more trusting of me because she knows that when I come here, I come, whereas at school she was constantly asking me what's going on sort of thing, mistrusting me.' With this trust came changes in other elements of social capital. Emily, for example, commented that she was having a hard time with her parents previously 'and since I left school and came here, I've actually been able to repair those relationships; they're actually enjoying having me around the house.' This was an example of a change in network structure, a change in the nature of a network membership, in this case her family network.

One final area worth documenting in relation to the outcomes of this program, is the reverse side perspective, the possible outcomes for some students had they not attended the program. This was not explored specifically in the interviews, but some students did speculate on what might have been, had they not participated in the program. Adam, for example, said: 'Oh yeah, it'd be a lot different, I'd still be smoking bongs.' Tom, in a fair bit of trouble at school, stated 'Like, I don't know, this helped me heaps, like otherwise I probably would be doing drugs or just in 
depression.' And Patrick said, 'I don't know what I would've done because I couldn't go back to school. I'm not sure I would have even tried to do my Year 10.'

In light of the reported disconnect between these students and the school system when they enrolled in the TAFE program, their (human capital) outcomes in terms of Year 10 completion, planned further studies and part time work, and social capital outcomes such as increased sense of efficacy, greater trust and generally relating better with adults and their own families, were significant. The interview data would suggest, at least for quite a number of students, a transformation in their lives - these human and social capital outcomes had improved their socioeconomic well-being in a number of indicator bands (as identified by the OECD 1982), including education and learning, employment and their social environment. How the overall learning environment contributed to these outcomes remains to be explained in the following sections of this paper.

\section{The learning environment}

There are two key elements of the learning environment which, broadly speaking, comprise the pedagogy in this TAFE program. These interrelated elements are, firstly, the individualised student focus within a flexible program structure, and secondly, the role of networks, and in particular the course-related learning network of teachers and students, and those involving peers. Individualised learning of itself is a common pedagogical approach, but what makes this approach in this study a little unusual, is that the individualised learning structure is nested within the broader and more diffuse learning environment of networks.

\section{Individualised learning within a flexible program structure}

All the students in the program worked on their own individualised program and sought assistance from teachers when they needed it. There was no group work undertaken, though previously there had been the occasional group work on aspects such as relationships and sex education. When students first started their course, they negotiated their program with a teacher, decided on the CGVE units and electives they were to study, and then mapped out their individual learning goals and expected progress. Students were assigned a mentor teacher, and at regular intervals there were progress meetings with teachers. All the study was self-paced and based on units of work drawn originally (though since modified) from a Year 10 distance education program, and the student work was assignment-based - there were no formal exams. The study area comprised three fairly small open access classrooms in which several teachers at a time were rostered and available to help students on a one-to-one basis as required. The aim of this classroom structure was for students to take responsibility for their own learning and meeting their negotiated learning goals, and to access teachers readily when needed.

This individualised learning was facilitated by the flexible program structure. The program was in fact known as 'CGVE flex' to distinguish it from other mainstream Year 10 programs operating in TAFE at the time. One aspect of its flexibility was the integration of literacy and numeracy with the CGVE course. All students were enrolled in both a literacy/numeracy course and the CGVE, but these courses were taught concurrently in an integrated manner, that is, literacy and numeracy were taught largely in the process of working on the various units of the CGVE course and not separately as discrete skills. This was important because, while most of the students experienced literacy and numeracy difficulties in formal education contexts, rather 
than focus on these difficulties within a deficit framework, the students worked primarily on achieving their stated goal, which was to complete their CGVE.

Another aspect of flexibility was the relative absence of the rule-bound routines associated with the school system. Students were timetabled to attend on specific days of the week, usually three days a week, though actual session times varied slightly according to circumstances. It was an adult learning environment in which students were expected to take responsibility for their learning, and hence it was an environment that could accommodate students leaving the study area for short breaks or some fresh air. Students could also enrol for the program at any time of the year and complete the course at any time, depending on their progress.

\section{A social capital approach to pedagogy}

We term this program a social capital approach to pedagogy due largely to the influence of the various networks to which students belonged, including peer networks, and the key influence from a pedagogical perspective, of the course-related learning network of teachers and students.

\section{Peer networks}

When students started this program at TAFE, they were introduced to new social networks with new norms and values. How the students managed their role within these networks, and in particular, whether they felt they were accepted and belonged in these networks, determined how they progressed in the course. How well they related with their new network of fellow peers seemed particularly important. The coordinator of the program made the observation that 'If they don't form a friendship almost straight away, then they are not going to last'. On this basis, some students didn't last and left the course very early, but those who were interviewed were current participants in the program and had made friends straight away. They indicated that making friends was quite easy, and acceptance and belonging in the peer network was not an issue, as the following two comments attest:

I made friends very quickly. Everyone here are nothing like students at school. They're accepting of people, really nice. (Patrick)

Actually, I made friends straight away. Oh yeah, first day. Everyone is just more, like, you know, in school they're a bit bitchy, and if you're not in the cool group, it's not ... here they're just nice, and it’s just more maturity type of thing. (Georgia)

Most students did not already know other students at TAFE, and for some it was a completely different social scene. Olivia, for example, said 'I've made heaps of friends here, my entire social grouping has changed. I'm doing a lot better now because I'm not hanging about with the bad kind of people.'

\section{The course-related teacher-student network}

At least as significant as peer groups, and probably more so in relation to the educational outcomes for students, was the course-related network of teachers and students. This was the main network that the teachers could influence. But this was not the regular teaching network that involved a teacher and a whole class. As indicated previously, teachers were rostered on, so there could be three or four teachers at any one time in three classrooms helping individual 
students on a one-to-one basis. The students spoke of their relationship with their teachers in very positive terms. Typically, one student said, 'They're just friendlier. They don't hassle you' (Elle). Another student, in response to the question, 'What do you like best about coming to the program?' replied, 'I would have to say the teachers. I have a good relationship with them. Everyone’s friends here, everyone talks here, and I just like coming’ (Georgia).

These comments related to the formal pedagogical network of teachers and students in the classrooms, but there were also other less formal networks involving teachers and students in activities beyond the classrooms. For example, one of the teachers on the program invited a student to a weekend youth group that was quite independent of the TAFE program. On another occasion, the same teacher invited a student along to a popular music event because she had a spare ticket as her own daughter didn't want to attend. In another example, one of the students involved himself in a local drama group, and at one of his performances, several of the teachers came along to watch him. Further, these informal networks of teachers and students interacting together extended beyond the Year 10 course, with teachers commenting that ex-students often called in to the TAFE program just for a chat.

What remains to be considered in this paper is a more detailed explanation of this course-related learning network of teachers and students, examining the nature of the relationship they had with their teachers. In this section we draw mainly on comments from teachers.

A couple of the teachers mentioned the 'connection' and respect they had with individual students which may well differ from many formal school learning contexts. As one teacher explained:

They feel, I think, because the course is individualised, we treat them as individuals, and we do respect them. I think that they feel they're a somebody here, and they didn't feel that at school. They felt they were just one of the masses, there was no flexibility. But they do feel that here. They feel that we hear what they're saying ...

As another teacher explained, 'I think we act with them very naturally. But we joke, we have good laughs sometimes. We're warm ... We listen to them, to what they're saying, what they're thinking ...' The students appeared to generally respond well to this level of informality and to genuinely enjoy engaging with teachers. One of the students commented, 'Like, today's my day off work, but I'd rather come here than stay at home because I get to have a conversation with the teachers and have a laugh and still do my work.'

Another illustrative element to this 'connection' between teachers and students is how students respond when they meet teachers in the community or in the shopping centres. One teacher saw this as a measure of how she knows when she's done a good job: 'The first thing is they've got a CGVE. The second thing is, they're pleasant to you, and when they're out on the street they'll say hello ...' Linked to this comment, and also illustrating the student-teacher connection, another teacher explained her dilemma when female students insisted on hugging her when they met in the nearby shopping mall. The issue of reciprocation was difficult for this teacher, given the advice provided to teachers by Child Protection courses. She explained, 'We still hug them, but then we get nervous that we shouldn't be doing this. But I mean, if they make the move, how could you back away?' 
This is not to say that every student adapted seamlessly into their new networks and their participation was a success. Those who didn't make friends quickly, as indicated earlier, often left the program early with little benefit from the program. And inevitably there were teething problems as some students initially expected confrontation with teachers, and others, while they enjoyed the program's social environment, found that actually re-engaging with formal study took a lot longer. One student, Georgia, said that at the beginning of the course, 'I didn't really come at all, for three months straight I didn't come'. But later she changed, and started attending all the time, 'Now I got my life planned out and I kinda know what I want to do'.

A key aspect of a social capital approach to pedagogy, certainly in the area of adult literacy and numeracy, is the establishment of classroom norms that ensure students feel safe to explore new learning opportunities. As the authors have previously stated, adult literacy and numeracy teachers who apply a social capital approach to their teaching establish norms with their learners that:

produce a social-emotional environment in which tolerance and good manners prevail; in which new students are welcomed; where students feel safe to take risks and share; where people listen patiently when others talk; and where being non-judgemental is paramount (Balatti, Black and Falk 2006:35).

We have previously referred to this learning environment as a 'practice field' (Balatti, Black and Falk 2006: 36) for students to play out new aspects of identity. We have already outlined aspects of this 'practice field' in terms of the new relationships students establish with teachers that was different to their former experiences with 'authority figures' at school. As suggested in the above quotation, another important element of this learning environment is tolerance to difference, and in this TAFE program for young people, there was a specific policy understood by all, that there was to be no 'bagging'. As a teacher explained:

We've got all sorts of kids. We've got kids here that don't fit the mould. They might say something but they know you don't bag anyone here, there are no put-downs. So most of the kids feel pretty safe. Sometimes someone will say something, but if you pull them into line they know ... Oh, ok, I shouldn't have said that, because it's not fair. They know that. But they know that they're not going to be put down either ...

To 'pull them into line' in this case may well involve nothing more than a reminder to them or the class as a whole that 'bagging' others was not part of the classroom norms. Another important element of classroom norms was the absence of embarrassment at requesting help from a teacher. The individualised structure of the program assisted this process because all students were working at their own pace on their individualised programs. As one teacher noted, 'There's no stigma attached if you're really struggling with your maths and you need one of us to sit with you.'

This last example and others showed that how teachers interacted and connected with students had a lot to do with the flexible, individualised program structure in this TAFE program, and that these two aspects went hand in hand. Teachers found they could relate informally and in a relaxed manner with students partly because they were not bound to enforce rigid rules involving, for example, dress codes, late passes, and permission slips to go to the toilet, that were typically found in school-based learning environments. 
The underlying pedagogical philosophy was that, within the bounds of teacher accountability, it was up to them; the students to take greater responsibility for their own behaviour. The teacher's role was to be as supportive as possible, to encourage them along and to remind them at times (sometimes often and quite directly) that they were falling behind in their goals. It was the program structure with its focus on students working towards their individualised goals that enabled teachers to not constantly be telling students to do things, as one teacher explained:

I don’t just say, you do ... because that doesn’t work with these kids. That's how school was and school didn’t work, so you set yourself up for conflict. The learning that comes from them now has to come from them wanting to learn. So, if they're outside and I go to round them up to get them in, I don't say, you've got to come ... I'll say, ok, your goal is ... now, are we going to meet those goals, you've got two week's left ...? So, it's all the time making them make the decision, take responsibility for their learning ...

The sense of efficacy demonstrated earlier in some of the student quotations was likely to be the result in part from teachers continually reinforcing the personal responsibility of students for achieving their own learning goals. Teachers explained that their role was to believe in their students, to be non-judgemental and supportive and when necessary, to 'put it back to them' and remind them they were letting themselves down.

\section{CONCLUSIONS}

The program that was the case in this study adopted a pedagogical approach that combined individualised learning and learning through networks. The learning outcomes experienced by students in the course were human capital outcomes such as improved skills and educational qualifications and social capital outcomes such as improved interactions with adults and peers. The data provided evidence of the impact of the program on the socio-economic well-being of students, especially in the areas of education and learning, employment and their social environment. However, VET reporting systems generally document only the human capital outcomes from these courses. There is very little acknowledgement or recognition, except privately by those teachers and students on the program itself, of the social capital outcomes and the role of pedagogical aspects which enhance the production of social capital outcomes (Balatti, Black and Falk 2006).

This study reinforces the view that neither human capital outcomes nor social capital outcomes should be viewed in isolation. Rather, these two forms of capital are mutually reinforcing. To provide just one example, a teacher explained how, in the process of learning new academic skills and achieving success in their course modules (i.e. human capital skills), students changed in ways that affected their interactions and possible links with new networks:

... as they start achieving in the course, they start to feel more confident about themselves, their self esteem grows. And therefore it's not so much the world is against them, and suddenly, they feel a really big power. They've got Year 10 and that gives them a few choices they haven't had before ... A lot of them build friendships from the course. A lot of them just look at the world really (as) more possibilities for them in it. 
By the same token, it would be easy to argue that the course learning (human capital) wouldn't occur without the 'connection', the warm relationship teachers and students established with each other (social capital) in their shared learning network. As the same teacher stated:

And the fact that they have that relationship is what keeps them here. To get through the course, you know what I mean? If they felt they were just another number and we didn't care, and it's probably going to be like school ... you know, that connection ...

In our previous study (Balatti, Black and Falk 2006:23-29), we provided other examples of the different interrelationships between social and human capital outcomes from adult literacy and numeracy courses which have an impact on the socio-economic well-being of students. The point to be reinforced is that hitherto neglected social capital outcomes are important for socioeconomic well being and therefore knowing more about how particular forms of pedagogy enhance the production of social capital is also important. In the case of this TAFE program for young people, it was the nature of the relationships, the network qualities between teachers and young people in their shared learning network, that appeared to have a major influence on producing social capital outcomes.

In summary, this paper has provided interview evidence that young people from this TAFE program have re-connected with the learning process. The program has turned young people, disaffected by their previous schooling experiences, into connected/engaged students working towards their Year 10 qualification and in quite a few cases, with aspirations for further studies. In some cases, students re-connected with their parents, and in the case of several students who were particularly rebellious at school, they had, in a sense, re-connected with the broader community. Teachers spoke of students feeling better about themselves and losing the 'chip on the shoulder' which some of them carried with them from school. The pedagogical model that resulted in these outcomes involved a flexible program structure based on individualised learning that also acknowledged students as members of networks in which both the teachers and students aspired to the norm of respectful interaction.

\section{REFERENCES}

ACT Department of Education and Training (2009) Pathways to the future: A report on the consultation on increasing young people's engagement in education, training and work, Australian Capital Territory Department of Education, Canberra.

Australian Bureau of Statistics (2004) Measuring social capital: An Australian framework and indicators, Information paper cat.no.1378.0, Australian Bureau of Statistics, Canberra.

Balatti, J and Black, S (forthcoming) 'Constructing learners as members of networks' in Catts, R, Falk, I and Wallace, R (eds) Vocational learning: Innovative theory and practice, Springer, Berlin.

Balatti, J, Black, S and Falk, I (2006) Reframing adult literacy and numeracy course outcomes: A social capital approach, National Centre for Vocational Education Research, Adelaide.

Balatti, J, Black, S and Falk, I (2009) A new social capital paradigm for adult literacy: Partnerships, policy and pedagogy, National Centre for Vocational Education Research, Adelaide. 
Bandura, A (1995) Self-efficacy in changing societies, Cambridge University Press, Cambridge.

Bassani, C (2007) 'Five dimensions of social capital theory as they pertain to youth studies', Journal of Youth Studies, vol 10, no.1, 17-34.

Bexley, E, Marginson, S and Wheelahan, L (2007) Social capital in theory and practice: The contribution of Victorian tertiary education in the 'new economy' disciplines of business studies and IT, University of Melbourne, Melbourne, viewed 1 November 2010, http://www.cshe.unimelb.edu.au/pdfs/SocialCapitalNov2007.pdf

Bourdieu, P (1986) 'The forms of capital' in Richardson, J (ed) Handbook of theory and research for the sociology of education, Greenwood Press, Ithaca.

Bradshaw, D (1999) Life is respect: Youth in ACE, Adult Community and Further Education, Northern Metropolitan Region, Melbourne.

Catts, R (2009) Social Capital and Employability, paper delivered at the AVETRA national conference, Coogee, viewed 20 February 2010, http://www.avetra.org.au/papers2009/papers/107.00.pdf

Chodkiewicz, A, Widen, J and Yasukawa, K (2010) 'Making connections to re-engage young people in learning: Dimensions of practice’, Literacy and Numeracy Studies, vol 18, no.1, 35-51.

Coleman, J (1988) 'Social capital in the creation of human capital', American Journal of Sociology, vol 94, Supplement S, 95-120.

Lumby, J (2007) '14- to 16-year-olds in further education colleges: Lessons for learning and leadership’, Journal of Vocational Education and Training, vol 59, no.1, 1-18.

OECD (Organisation for Economic Cooperation and Development) (1982) The OECD list of social indicators, OECD, Paris.

OECD (Organisation for Economic Cooperation and Development) (2001) The well-being of nations: The role of human and social capital, OECD, Paris.

Portes, A (1998) 'Social capital: Its origins and applications in modern sociology', Annual Review of Sociology, vol.24, 1-24.

Putnam, D (2000) Bowling alone: The collapse and revival of American community, Simon \& Schuster, New York.

Raffo, C (2003) Disaffected young people and the work-related curriculum at Key stage 4: Issues of social capital development and learning as a form of cultural practice, Journal of Education and Work, vol. 16, no.1 69-86.

Rodd, $\mathrm{H}$ and Stewart, $\mathrm{H}$ (2009) 'The glue that holds our work together: The role and nature of relationships in youth work', Youth Studies Australia, vol 28, no.4, 4-10. 
Spielhofer, T, Marson-Smith, H and Evans, K (2009) Non-formal learning: Good practice in reengaging young people who are NEET, National Foundation for Educational Research, Slough.

Stanton-Salazar, R (1997) 'A social capital framework for understanding the socialization of racial minority children and youths’, Harvard Educational Review vol. 67, no.1, 1-40.

Volkoff, V, Keating, J, Walstab, A and Marr, B (2006) Effective TAFE, ACE and private provider delivery to young people, 15-24 years old, Victorian Learning and Employment Skills Commission, East Melbourne. 